\title{
The Relationship of Physical Support, Personnel Contact and Image toward Patients' Trust to Hospital
}

\author{
Juli Prastyorini
}

Sekolah Tinggi Ilmu Administrasi Kepelabuhanan (STIAMAK) Barunawati Surabaya, Indonesia

\begin{abstract}
The aim of this study is to examine the influence of Physical Support, Personnel Contact and Image toward Patients' Trust to Hospital either individually or jointly. Variables of Physical Support, Personnel Contact and Image as independent variables while the dependent variable is Patients' Trust. The research was conducted on proportional randomly selected 150 outpatients of Al-Irsyad Hospital in Surabaya region, East Java, Indonesia. Using path analysis, the study reveals that there is a positive significant relationship among variables under the following path coefficient : Physical Support --> Patients' Trust $=0.552$, Personnel Contact $->>$ Patients' Trust $=0.468$, Image --> Patients' Trust $=0.454$ and when tested together producing coefficient of determination $=0.424$ indicating the existence of other $57.6 \%$ variables not including in the model affecting Patients' Trust toward the trust in private hospital.
\end{abstract}

Keywords: Physical Support, Personnel Contact, Image, Patients' Trust, Hospital

\section{INTRODUCTION}

In today's competitive health care industry, hospital administrators would like to determine how important service attributes are to potential consumers and how those attributes influence consumer choice decisions. The ability to provide accessible and cost-effective health services to patients depends on a thorough understanding of the factors associated with the choice and use of services, especially those factors which can be manipulated to improve the provision of health care services. To understand why patients choose one hospital over another, it is important to understand the major factors that patients consider. Earlier studies on factors influencing patients choice of a hospital were limited in many countries, especially the developing ones like Indonesia. In traditional societies of the developing world, the set of determinant variables for the utilisation of health services seems to be more complex than in the developed countries. Additional factors are involved due to: cultural differences, which include the change of illness concepts and health behaviour; the existence of a wide range of health services, both in quality and quantity; and the different socio demographic conditions.

In Indonesia, most studies identify nearly similar factors influencing the choice of hospitals by referring to service quality, but the differences are in arranging these factors from the most important to the less important. Health services included in the health services industry plays an important role. The hospital is one form of organizations in the health service industry in the field of health care where one of the efforts is to support the basic level services, such as health centers. Therefore, as a referral center basic level of health care, the hospital services need maintain the quality of services to communities in need. The health systems are different from province to province due to decentralization system and the framework and classification of these studies are different. However, very limited study is found on private hospital. Physician-hospital interdependence has switched from a symbiotic to a competitive basis. In response, hospitals are seeking ways to control or influence their physicians' utilization behavior and to integrate them more closely into hospital affairs in terms of physical support, personnel contact and image of the hospital.

Based on the background and the results of the identification of the problem, the formulation of the problem is:

1. Does physical support positively affect patients trust to private hospital?

2. Does positively affect patients trust to private hospital? 
3. Does image positively affect patients trust to private hospital?

4. Do physical support, personnel contact and image positively altogether affect patients trust to private hospital?

\section{Literature REVIEW}

Nursing Support and Personal Care Workers provide assistance, support and direct care to patients in a variety of health, welfare and community settings. Greater patient acuity, increased pressure on beds, the imperative of performance targets, and meeting the requirements of numerous external and regulatory bodies have all had an impact on the environment of patients' care. Nurses are factors that have an important role in stress management, especially in facilitating and directing the patients to cope constructively so that patients can adapt to the pain by giving social support, in the form of emotional support, information, and material Wagner and Bear, 2009). In an environment that has often been characterised as "what matters is what's measured" (Bevan and Cornwel, 2006), nursing may be deemed unimportant until cases of poor care emerge, resulting in investigations, disciplinary action and blame. The role of the nurse involves supporting people when they are distressed, suffering and dying. Nurses provide 24- hour continuous care for patients, all year round and feel the full, immediate, and concentrated impact of the stresses arising from patient care. Their work involves carrying out tasks which, by ordinary standards, are distasteful, disgusting and frightening.

A close relationship in terms of personnel contact can predict health. Risks in greater health occur in people who are lonely as they often experience stress, lack of sleep, and tried to commit suicide. Compared to those who have little social ties, those who have a close relationship with his friends, relatives, or other members and religious organizations or community are fewer who want to end life faster (Myers et.al, 2012). Married people also tend to live healthier and live longer than people who are not married. National for Health Statistics reported that people, no matter what age, gender, race and income, tend to be healthier if married. People who are married have fewer headaches and back pain, suffering a bit stressful, as well as a little drinking alcohol and smoking. This prove that there is a contribution from personnel contact to suppress the emergence disease (Myers, et.al, 2012). Social support and personnel contact also affect health. Those who enjoy a close relationship can consume foods with better, exercise more, and reduce alcohol consumption and smoking as friends and families help improve their self-esteem.

Trust is credibility, promises and goodness of hospital expected or perceived by customer. If the trust is established, commitment and relationship between the hospital and the customer has the potential to become beneficial each other (Alrubaiee \& Feras, 2011). Trust will be stronger when the hospital is more responsive to customer needs and to participate as well as to assure the needs of customers resulting in positive world of mouth which improve the image and bring benefits for the hospital (Alrubaiee \& Feras 2011).

The image of the hospital is affected by many things, among others, the high quality of service, good facilities, comfortable environment, hospital history, costs, attitude of doctors, sophisticated medical equipment, past experience, word of mouth, and marketing communications (Kim, et al., 2008). According Petzer and De Meyer (2012), when hospitals can not provide good service to patients, it will be cause dissatisfaction in patients. Patient will complain creating negative word of mouth and forming a bad image in the community surroundings. According Andaleeb (2001), an increase the quality of communication between the hospital with customers, will strengthen the commitment to the relationship, customers will feel more satisfied, so it will improve the image of the hospital.

Based on above description, hypothesis formulated is: physical support significantly affects trust to private hospital (H1), personnel contact significantly affects trust to private hospital (H2), image significantly affects trust to private hospital (H3), physical support, personnel contact and image affect trust to private hospital simultaneously $(\mathrm{H} 4)$.

\section{Data Collection}

This study applies explanatory quantitative method with direct observation to the field aimed at analyzing the cause and effect of phenomenon. The sample of this study were 150 outpatients visiting Al-Irsyad Hospital Surabaya. This way the writer applied purposive sampling.

Techniques of data collection in this study is in the form of questionnaire. The normality assumption is prerequisites to proceed to further test. Analysis is conducted with multiple linear regression and hypothesis testing is performed at a significance level of 0.05 . 


\section{RESUlT AND DISCUSSION}

The respondents s were asked to participate in the survey by stating their opinions for four different measures on physical support, personnel contact, image and trust to private hospital. The normality is performed with Lilliefors test. Data are normally distributed as the value of each variable is not exceeding the critical value for Lilliefors test. The Lilliefors normality test values for physical support, personnel contact, image and trust to private hospital are 0.064, 0.662 and 0.092 respectively below the critical value of 0.130 for $n=150$. The reliability test for each choice factor was run to determine how strongly the attributes were related to each other. Cronbach Alpha value should be greater than 0.7 for a scale to be reliable (Hair et al., 2006). In the present study, the overall reliability of the reduced scale was found to be 0.76 . Factor wise, the Cronbach Alpha value was found to be 0.84 for physical support, 0.72 for personnel contact, 0.74 for image , and 0.76 for trust. The values suggest internal consistency of the scale.

\subsection{The Effect of Physical Support to Trust}

Hypothesis testing confirms that physical support positively affects trust with correlation coefficient value of 0.552 and the coefficient of determination $=0.304$. This means that only $30.4 \%$ of trust is determined by physical support, while the other $69.6 \%$ is contributed by other variables. This finding strengthens the finding of Ommen et. al, (2008) who found that trust is an important aspect of physician-patient-interaction, both in terms of compliance and patient- and physician-reported outcomes. Trust-building communication is especially important in terms of severely injured patients because of severity of their injuries and frequently associated physical and psychological consequences. Patients preferences concerning medical treatment (patient type) is also regarded to be important in terms of trust.

\subsection{The Effect of Personnel Contact to Trust}

Hypothesis testing confirms that personnel contact positively affects trust in private hospital with correlation coefficient value of 0.468 and the coefficient of determination $=0.219$. This means that only $21.9 \%$ of trust is determined by personnel contact, while the other $78.1 \%$ is contributed by other variables. This finding strengthens Rahmadhani (2013) who found the variables of facilities and infrastructure and personal contact had influence on the patients' trust in Dr. H. Yuliddin Away General Hospital Tapaktuan, Medan, Indonesia. Facilities and infrastructure were the most dominant factors influencing the patients' trust.

The management is suggested to complete the facilities and infrastructure needed in the implementation of health service by adjusting the health facilities to the medical equipment technology development, and to improve the personal contact between the hospital staff and the patients through the improvement of professionalism and staff's attitude in communicating and interacting with the patients.

\subsection{The Effect of Image to Trust}

Hypothesis testing confirms that image positively affects trust in private hospital with correlation coefficient value of 0.454 and the coefficient of determination $=0.206$. This means that only $20.6 \%$ of trust is determined by image, while the other $79.4 \%$ is contributed by other variables. This finding strengthens the finding of Muhlis and Dewanto (2013) using the variables of trust, customer satisfaction, and relationship commitment as the independent variables and hospital image as the dependent variable. The results showed that the trust, customer satisfaction, and relationship commitment influence either partially or simultaneously to the hospital image. Customer satisfaction was a dominant variable compared of trust and relationship commitment.

\subsection{Interaction of Physical Support, Personnel Contact and Image to Patients' Trust}

When tested together, hypothesis testing results show that there is a significant relationship between physical support, personnel contact and image to patients' trust in private hospital with the coefficient of determination $=0.424$. This means that $42.4 \%$ of trust in private hospital is determined by variables of physical support, personnel contact and image while $57.6 \%$ is contributed by other variables not included in the model. Prior work, mostly done overseas, highlights the fact that there are numerous factors that influence a customer's choice of a hospital. However, scholars have argued that choice factors vary across countries (Daida et al., 2013). Due to differences in the culture, context, national characteristics, insurance policies, and health care delivery system, all choice factors identified overseas may not necessarily have the same relevance in the Indonesian context. 
Furthermore, studies conducted in a different context may lead to the emergence of new factors not considered in prior work. This research attempts to investigate some of the factors patients or their relatives considered important in choosing a health care provider in second largest cities in Indonesia.

\section{CONClusion}

The findings reveal that there is a positive and significant direct effect between the physical support, personnel contact and image to trust.

Based on the initial design of the constellation between variables, the results showed that the contribution of physical support to trust is $30.4 \%$, personnel contact is $20.6 \%$, and image is $21.9 \%$ indicating the highest individual contribution to the trust is physical support. When combined together, contribution of the three variables reaches $42.4 \%$ indicating the contribution of other variables not included in the model to predict performance are $58.6 \%$ indicating this model is of marginal-fit. Other researchers wishing to conduct similar studies may include other variables such as; availability of physicians and surgeons, infrastructure, security, suggestion from relatives and friends, referral by doctors, transport convenience, nearness to home, cost, media influence, patient urgency, and reimbursement facility and so forth.

\section{REFERENCES}

Alrubaiee, Laith, and Feras Alkaa'ida. "The mediating effect of patient satisfaction in the patients' perceptions of healthcare quality-patient trust relationship." International Journal of Marketing Studies 3, no. 1 (2011): 103.

Andaleeb, Syed Saad. "Service quality perceptions and patient satisfaction: a study of hospitals in a developing country." Social science \& medicine 52, no. 9 (2001): 1359-1370.

Bevan, G., \& Cornwell, J. (2006). Structure and logic of regulation and governance of quality of health care: was OFSTED a model for the Commission for Health Improvement?. Health Economics, Policy and Law, 1(04), 343-370.

Daida, H., Miyauchi, K., Ogawa, H., Yokoi, H., Matsumoto, M., Kitakaze, M., ... \& Tsukahara, K. (2013). Management and Two-Year Long-Term Clinical Outcome of Acute Coronary Syndrome in Japan. Circulation Journal, 77(4), 934-943.

Hair, J. F., Black, W. C., Babin, B. J., Anderson, R. E., \& Tatham, R. L. (2006). Multivariate data analysis (Vol. 6).

Kim, K. H., Kim, K. S., Kim, D. Y., Kim, J. H., \& Kang, S. H. (2008). Brand equity in hospital marketing. Journal of business research, 61(1), 75-82.

Myer, Gregory D., Avery D. Faigenbaum, Andrea Stracciolini, Timothy E. Hewett, Lyle J. Micheli, and Thomas M. Best. "Exercise deficit disorder in youth: a paradigm shift toward disease prevention and comprehensive care."Current sports medicine reports 12, no. 4 (2012): 248-255.

Muchlis, M., \& Dewanto, A. (2013). Pengaruh Kepercayaan, Kepuasan Pelanggan dan Komitmen Hubungan terhadap Citra Rumah Sakit di Kota Blitar. Jurnal Aplikasi Manajemen, 11(3), 469-480.

Ommen, O., Janssen, C., Neugebauer, E., Bouillon, B., Rehm, K., Rangger, C., ... \& Pfaff, H. (2008). Trust, social support and patient type-Associations between patients perceived trust, supportive communication and patients preferences in regard to paternalism, clarification and participation of severely injured patients. Patient education and counseling, 73(2), 196-204.

Petzer, D. J., De Meyer, C. F., Svari, S., \& Svensson, G. (2012). Service receivers' negative emotions in airline and hospital service settings. Journal of Services Marketing, 26(7), 484496.

Rahmadhani, M. (2013). Pengaruh Sarana dan Prasarana Serta Kontak Personal terhadap Kepercayaan Pasien di Rumah Sakit Umum Daerah dr. H. Yuliddin Away Tapaktuan (Master Theses).

Wagner, D., \& Bear, M. (2009). Patient satisfaction with nursing care: a concept analysis within a nursing framework. Journal of advanced nursing, 65(3), 692-701. 